\title{
A new furaquinocin derivative, JBIR-136, from Streptomyces sp. $4963 \mathrm{H} 2$
}

\author{
Teppei Kawahara ${ }^{1}$, Aya Nagai ${ }^{1}$, Motoki Takagi ${ }^{1}$ and Kazuo Shin-ya ${ }^{2}$ \\ The Journal of Antibiotics (2012) 65, 579-581; doi:10.1038/ja.2012.72; published online 29 August 2012
}

Keywords: cytotoxicity; furaquinocin; Streptomyces

Natural products are considered to be good sources for the screening of lead compounds of clinical drugs. We performed a large number of drug screenings by using a variety of assay systems with crude extracts of microbial cultures as a traditional natural product library. In some assay systems, our crude extract library could not work effectively. With this in mind, we started to construct a purified natural compound library possessing various skeletons from cultures of microorganisms. As actinomycetes are known to produce pharmaceutically useful compounds, ${ }^{1,2}$ we focused mainly on secondary metabolites from cultures of actinomycetes. To achieve this, we established a high-throughput system for the detection of secondary metabolites from the cultures of actinomycetes with the retentiontime and HR-MS data of known compounds by using a UPLC-TOFMS system (Waters, Milford, MA, USA). ${ }^{3}$ We analyzed the secondary metabolites, including potential novel compounds, present in the cultures of the strains isolated from a variety of resources by this system. ${ }^{3}$ In the course of our chemical screening program, a new furaquinocin derivative named JBIR-136 (1, Figure 1a), together with the known compound kujimycin $\mathrm{A}^{4}$ was isolated from a culture broth of Streptomyces sp. 4963H2. This paper describes the fermentation, isolation, structural elucidation and, in brief, the biological activity of $\mathbf{1}$.

Streptomyces sp. $4963 \mathrm{H} 2$ was isolated from a soil sample collected in Kimitsu, Chiba Prefecture, Japan. The strain was cultivated in $50-\mathrm{ml}$ test tubes, each containing $15 \mathrm{ml}$ of a seed medium consisting of $1.0 \%$ starch (Kosokagaku, Tokyo, Japan), 1.0\% polypeptone (Nihon Pharmaceutical, Tokyo, Japan), 1.0\% molasses (Dai-Nippon Meiji Sugar, Tokyo, Japan) and 1.0\% meat extract (Extract Ehlrich, Wako Pure Chemical Industry, Osaka, Japan) at pH 7.2 (adjusted before sterilization). The test tubes were shaken on a reciprocal shaker (320 r.p.m.) at $27^{\circ} \mathrm{C}$ for 2 days. Aliquots $(2.5 \mathrm{ml})$ of the broth were transferred to $500-\mathrm{ml}$ baffled Erlenmeyer flasks containing $100 \mathrm{ml}$ of a production medium consisting of $2.0 \%$ glycerol (Nacalai Tesque,
Kyoto, Japan), 1.0\% molasses (Dai-Nippon Meiji Sugar), 0.5\% casein (Kanto Chemical, Tokyo, Japan), $0.1 \%$ polypeptone (Nihon Pharmaceutical) and $0.4 \% \mathrm{CaCO}_{3}$ (Kozaki Pharmaceutical, Tokyo, Japan) at $\mathrm{pH} 7.2$ (adjusted before sterilization), and were cultured on a rotary shaker ( 180 r.p.m.) at $27^{\circ} \mathrm{C}$ for 5 days.

The fermentation broth (21) was separated by centrifugation. The supernatant was partitioned between EtOAc and $\mathrm{H}_{2} \mathrm{O}(2 \mathrm{l} \times 3)$, whereas the mycelial cake was extracted with acetone $(50 \mathrm{ml})$ and filtered, and the filtrate was concentrated in vacuo. The residual aqueous concentrate was extracted with EtOAc (equal volume $\times 3$ ). The combined EtOAc layers were dried over $\mathrm{Na}_{2} \mathrm{SO}_{4}$, and then evaporated to dryness. The residue $(733 \mathrm{mg})$ was subjected to normalphase medium pressure liquid chromatography (Purif-Pack SI-30, Shoko Scientific, Yokohama, Japan) and developed successively with a gradient system of $n$-hexane-EtOAc $(0-15 \%$ EtOAc) followed by the stepwise solvent system of $\mathrm{CHCl}_{3}-\mathrm{MeOH}(0,2,5,10,20,30$ and $100 \% \mathrm{MeOH}$ ). The $5 \% \mathrm{MeOH}$-eluted fraction (91.3 mg) was then subjected to preparative reversed-phase HPLC on a CAPCELL PAK C18 MGII column $(5.0 \mu \mathrm{m}, 20$ i.d. $\times 150 \mathrm{~mm}$; Shiseido, Tokyo, Japan) with $60 \%$ aqueous $\mathrm{MeOH}$ containing $0.1 \%$ formic acid (flow rate: $10 \mathrm{ml} \mathrm{min}^{-1}$ ) to give $\mathbf{1}$ (7.2 $\mathrm{mg}$; retention time: $10.6 \mathrm{~min}$ ).

Compound 1 was a pale yellow amorphous solid $\left([\alpha]_{\mathrm{D}}^{24}-38, c 0.36\right.$ in $\mathrm{MeOH}$; UV $\lambda_{\max }(\varepsilon)$ in MeOH: 233 (17000), 281 (12000) and 316 (5600) $\mathrm{nm}$ ). The IR spectrum ( $v_{\max }$ (attenuated total reflectance) 3380 and $1652 \mathrm{~cm}^{-1}$ ) indicated the presence of hydroxy and carbonyl groups. The molecular formula was determined as $\mathrm{C}_{21} \mathrm{H}_{28} \mathrm{O}_{6}$ by highresolution ESI MS $\left(m / z 375.1790[\mathrm{M}-\mathrm{H}]^{-}\right.$, calcd for $\mathrm{C}_{21} \mathrm{H}_{27} \mathrm{O}_{6}$ 375.1808). The direct connectivity between protons and carbons was established by a heteronuclear single quantum coherence spectrum; the tabulated ${ }^{13} \mathrm{C}$ and ${ }^{1} \mathrm{H}$ NMR spectroscopic data for $\mathbf{1}$ are listed in Table 1. A planar structure was elucidated through the analysis of the DQF-COSY and constant-time (CT-HMBC) $)^{5}$ data, as described below.

\footnotetext{
${ }^{1}$ Biomedicinal Information Research Center (BIRC), Japan Biological Informatics Consortium (JBIC), Tokyo, Japan and ${ }^{2}$ Biomedicinal Information Research Center (BIRC), National Institute of Advanced Industrial Science and Technology (AIST), Tokyo, Japan

Correspondence: Dr M Takagi, Biomedicinal Information Research Centre (BIRC), Japan Biological Informatics Consortium (JBIC), 2-4-7 Aomi, Koto-ku, Tokyo 135-0064, Japan. E-mail: motokitakagi03@gmail.com

or Dr K Shin-ya, Biomedicinal Information Research Centre (BIRC), National Institute of Advanced Industrial Science and Technology (AIST), 2-4-7 Aomi, Koto-ku, Tokyo 135-0064, Japan.

E-mail: k-shinya@aist.go.jp

Received 2 April 2012; revised 2 July 2012; accepted 9 August 2012; published online 29 August 2012
} 
<smiles>CO[C@H]1CC(=O)c2c(cc(O)c3c2O[C@H](C)[C@@]3(C)[C@H](O)CC=C(C)C)[C@H]1O</smiles>
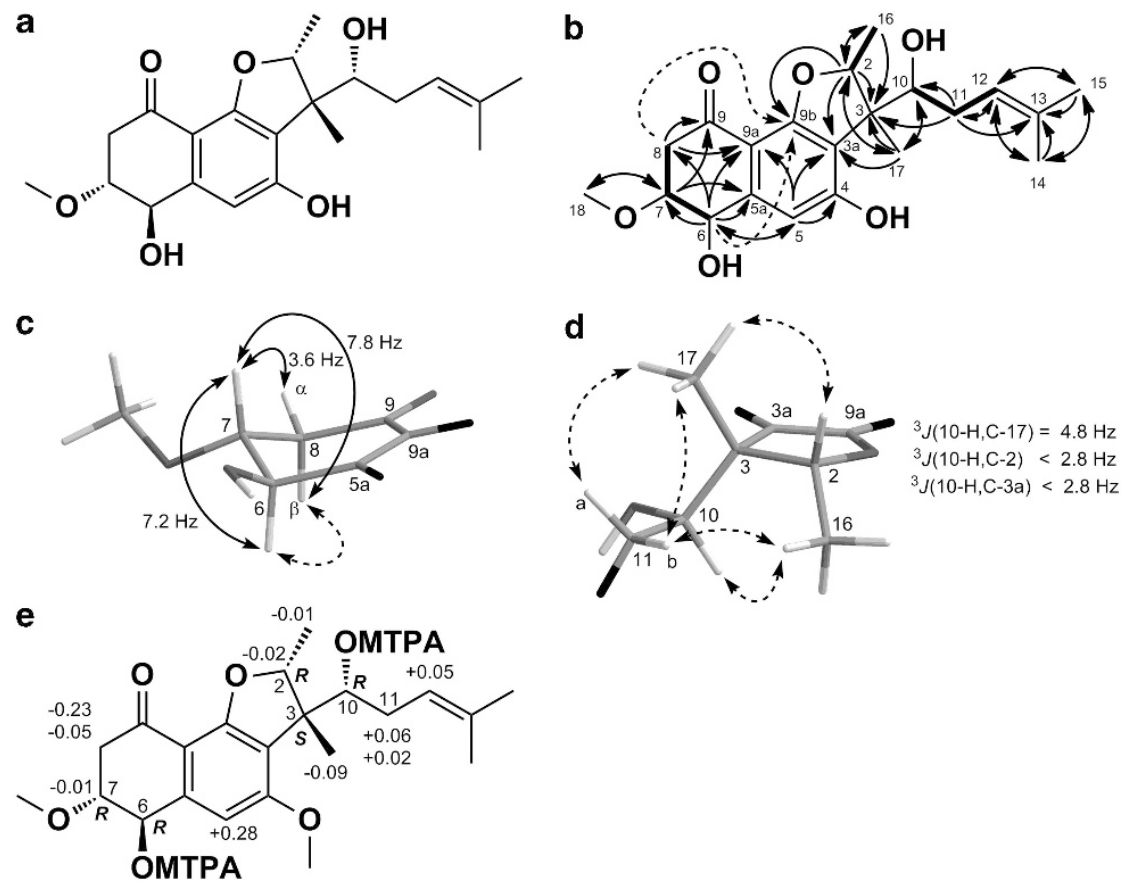

Figure 1 (a) Structure of JBIR-136 (1). (b) Key correlations of DQF-COSY (bold line) and HMBC (arrow; dashed arrow is four-bond coupling) for 1. (c) Selected NOESY correlations and ${ }^{1} \mathrm{H}-1{ }^{1} \mathrm{H}$ coupling constants of 4-hydroxy-5-methoxycyclohex-2-enone moiety of 1 (dashed arrow: NOESY correlation). (d) Relative configurations of C-2-C-3 and C-3-C-10 axes of 1 (dashed arrow: NOESY correlation). (e) $\Delta \delta$ values $\left(\Delta \delta\right.$ (in p.p.m.) $\left.=\delta_{S}-\delta_{R}\right)$ obtained for the (S)- and (R)-methoxy(trifluoromethyl)phenylacetic acid (MTPA) diesters of the methyl ester derivative of 1.

Table 1 NMR spectroscopic data $(600 \mathrm{MHz})$ for JBIR-136 (1)

\begin{tabular}{|c|c|c|}
\hline Position & $\delta_{C}$ & $\delta_{H}($ Multiplicity, J in $\mathrm{Hz}$ ) \\
\hline 2 & 89.2 & $4.58(q, 6.6)$ \\
\hline 3 & 53.3 & \\
\hline $3 a$ & 119.5 & \\
\hline 4 & 160.2 & \\
\hline 5 & 110.0 & $6.59(\mathrm{~s})$ \\
\hline $5 a$ & 146.9 & \\
\hline 6 & 71.4 & $4.63(d, 7.2)$ \\
\hline 7 & 81.1 & 3.62 (ddd, 3.6, 7.2, 7.8) \\
\hline 8 & 41.8 & $2.89 \alpha(\mathrm{dd}, 3.6,16.2) ; 2.42 \beta(\mathrm{dd}, 7.8,16.2)$ \\
\hline 9 & 191.4 & \\
\hline $9 a$ & 110.7 & \\
\hline $9 b$ & 162.0 & \\
\hline 10 & 74.9 & $4.00(d, 9.0)$ \\
\hline 11 & 33.5 & $2.44 \mathrm{a}(\mathrm{ovl})^{\mathrm{a}} ; 2.28 \mathrm{~b}(\mathrm{dd}, 7.2,15.6)$ \\
\hline 12 & 121.7 & $5.29(\mathrm{dd}, 7.2,7.2)$ \\
\hline 13 & 134.7 & \\
\hline 14 & 18.1 & $1.64(\mathrm{~s})$ \\
\hline 15 & 26.0 & $1.69(\mathrm{~s})$ \\
\hline 16 & 16.2 & $1.25(\mathrm{~d}, 6.6)$ \\
\hline 17 & 19.7 & $1.29(\mathrm{~s})$ \\
\hline 18 & 57.1 & 3.39 (s) \\
\hline
\end{tabular}

NMR spectra were taken on an NMR System 600 NB CL (Varian, Palo Alto, CA, USA) in acetone- $d_{6}$ with the residual solvent peak as an internal standard $\left(\delta_{C} 29.8, \delta_{H} 2.04\right.$ p.p.m.). averlapped with another peak.

The sequence from the oxymethine proton $6-\mathrm{H}\left(\delta_{\mathrm{H}} 4.63\right)$ to the methylene protons $8-\mathrm{H}_{2}\left(\delta_{\mathrm{H}} 2.89 ; 2.42\right)$ via the oxymethine proton $7-\mathrm{H}\left(\delta_{\mathrm{H}} 3.62\right)$ was observed in the DQF-COSY spectrum (Figure $\left.1 \mathrm{~b}\right)$. The CT-HMBC spectrum showed ${ }^{1} \mathrm{H}-{ }^{13} \mathrm{C}$ long-range correlations from $8-\mathrm{H}_{2}$ to the conjugated ketone carbonyl carbon C-9 $\left(\delta_{\mathrm{C}} 191.4\right)$ and the aromatic quaternary carbon $\mathrm{C}-9 \mathrm{a}\left(\delta_{\mathrm{C}} 110.7\right)$, from $7-\mathrm{H}$ to C-9 and the aromatic quaternary carbon C-5a $\left(\delta_{\mathrm{C}} 146.9\right)$, from $6-\mathrm{H}$ to $\mathrm{C}-5 \mathrm{a}$ and $\mathrm{C}-9 \mathrm{a}$ and from the methoxy proton $18-\mathrm{H}_{3}\left(\delta_{\mathrm{H}} 3.39\right)$ to the oxygenated methine carbon $\mathrm{C}-7\left(\delta_{\mathrm{C}} 81.1\right)$, indicating the presence of a 4-hydroxy-5-methoxycyclohex-2-enone moiety. In addition, strong $m$-couplings from the aromatic methine proton $5-\mathrm{H}\left(\delta_{\mathrm{H}}\right.$ $6.59)$ to the aromatic quaternary carbons $\mathrm{C}-3 \mathrm{a}\left(\delta_{\mathrm{C}} 119.5\right)$ and C-9a, together with HMBC correlations to the oxygenated aromatic carbon C-4 $\left(\delta_{\mathrm{C}} 160.2\right)$ and the oxymethine carbon C-6 $\left(\delta_{\mathrm{C}} 71.4\right)$, and weak four-bond $\mathrm{w}$-shaped couplings from $8-\mathrm{H} \alpha$ and $6-\mathrm{H}$ to the oxygenated aromatic carbon C-9b $\left(\delta_{\mathrm{C}} 162.0\right)$ were observed, indicating the presence of a benzene ring substructure.

The presence of a monoterpene unit was elucidated as follows. A 3-isopropylidenepropanol moiety (from $\mathrm{CH}-10$ to $\mathrm{CH}_{3}-15$ ) was established by the spin systems from the oxymethine proton $10-\mathrm{H}$ $\left(\delta_{\mathrm{H}} 4.00\right)$ to the olefinic methine proton $12-\mathrm{H}\left(\delta_{\mathrm{H}} 5.29\right)$ through the aliphatic methylene protons $11-\mathrm{H}_{2}\left(\delta_{\mathrm{H}} 2.44,2.28\right)$, and ${ }^{1} \mathrm{H}-{ }^{13} \mathrm{C}$ longrange correlations from the two sets of allylic methyl protons $14-\mathrm{H}_{3}$ $\left(\delta_{\mathrm{H}} 1.64\right)$ and $15-\mathrm{H}_{3}\left(\delta_{\mathrm{H}} 1.69\right)$ to the olefinic methine carbon $\mathrm{C}-12$ $\left(\delta_{\mathrm{C}} 121.7\right)$ and olefinic quaternary carbon $\mathrm{C}-13\left(\delta_{\mathrm{C}} 134.7\right)$, as obtained from the DQF-COSY and CT-HMBC spectra, respectively. The assignments of $\mathrm{C}-14$ and $\mathrm{C}-15$ were established because of the $\gamma$-effect at $\mathrm{C}-14\left(\delta_{\mathrm{C}} 18.1\right) .{ }^{1} \mathrm{H}-{ }^{13} \mathrm{C}$ long-range couplings from the singlet methyl proton $17-\mathrm{H}_{3}\left(\delta_{\mathrm{H}} 1.29\right)$ to the quaternary carbon $\mathrm{C}-3$ $\left(\delta_{\mathrm{C}} 53.3\right)$, the aromatic quaternary carbon $\mathrm{C}-3 \mathrm{a}$, the oxymethine carbon $\mathrm{C}-10\left(\delta_{\mathrm{C}} 74.9\right)$ and the oxymethine carbon $\mathrm{C}-2\left(\delta_{\mathrm{C}} 89.2\right)$ revealed that the 3 -isopropylidenepropanol and benzene moieties were interconnected through $\mathrm{C}-3 .{ }^{1} \mathrm{H}-{ }^{1} \mathrm{H}$ coupling between the oxymethine proton $2-\mathrm{H}\left(\delta_{\mathrm{H}} 4.58\right)$ and methyl protons $16-\mathrm{H}_{3}\left(\delta_{\mathrm{H}}\right.$ 1.25 ) and the ${ }^{1} \mathrm{H}-{ }^{13} \mathrm{C}$ long-range correlation from the methyl proton $16-\mathrm{H}_{3}$ to $\mathrm{C}-3$ were evident in the DQF-COSY and CT-HMBC spectra, 
respectively. In addition, the $\mathrm{HMBC}$ coupling from the oxymethine proton $2-\mathrm{H}$ to the aromatic carbon $\mathrm{C}-9 \mathrm{~b}$ established that these carbons were connected through an ether bond. The index of hydrogen deficiency of eight allowed the final determination of the structure of 1, as shown in Figure 1a.

The relative configuration of $\mathbf{1}$ was determined from NOESY and the $J$ values. From the ${ }^{1} \mathrm{H}$ NMR spectrum, large coupling constants of ${ }^{3} J_{6-\mathrm{H}, 7-\mathrm{H}}=7.2 \mathrm{~Hz}$ and ${ }^{3} J_{7-\mathrm{H}, 8-\mathrm{H} \beta}=7.8 \mathrm{~Hz}$ and a small coupling value of ${ }^{3} J_{7-\mathrm{H}, 8-\mathrm{H} \alpha}=3.6 \mathrm{~Hz}$ were obtained. The NOESY spectrum showed a correlation between $6-\mathrm{H}$ and $8-\mathrm{H} \beta$. On the basis of these data, $6-\mathrm{H}$, $7-\mathrm{H}$ and $8-\mathrm{H} \beta$ are found to be in pseudoaxial positions, whereas $8-\mathrm{H} \alpha$ and $\mathrm{O}-7$ are in pseudoequatorial positions, as shown in Figure 1c. The NOESY correlation of $2-\mathrm{H} / 17-\mathrm{H}$ implied that $\mathrm{CH}_{3}-16$ and $\mathrm{CH}_{3}-17$ were in the trans orientation. For the $\mathrm{C}-3 / \mathrm{C}-10$ axis, NOESY correlations from $11-\mathrm{H}_{2}$ to $16-\mathrm{H}$ and $17-\mathrm{H}$ showed gauche orientation between C-11 and C-17. Furthermore, a strong NOESY correlation between $10-\mathrm{H}$ and $16-\mathrm{H}$ was seen, whereas no correlation was observed for $10-\mathrm{H} / 17-\mathrm{H}$, indicating gauche orientation between $\mathrm{C}-17$ and the oxygen atom $\mathrm{O}-10$. On the other hand, ${ }^{1} \mathrm{H}-{ }^{13} \mathrm{C}$ coupling constants of ${ }^{3} J_{10 \mathrm{H}-\mathrm{C} 17}=4.8 \mathrm{~Hz},{ }^{3} J_{10 \mathrm{H}-\mathrm{C} 2}<2.8 \mathrm{~Hz}$ and ${ }^{3} J_{10 \mathrm{H}-\mathrm{C} 3 \mathrm{a}}<2.8$ $\mathrm{Hz}$ were obtained from the analysis of the J-resolved HMBC-2 spectrum. ${ }^{6}$ According to the J-based configuration analysis method, ${ }^{7}$ this result strongly supported the relative configuration described above. Taken together, the relative configurations at C-2, C-3 and C-10 were elucidated to be $R^{\star}, S^{*}$ and $R^{*}$, respectively, as shown in Figure 1d.

The absolute configuration of $\mathbf{1}$ was determined using a modified Mosher's method $^{8}$ after O-methylation with trimethylsilyldiazomethane in $\mathrm{MeOH}$ to afford a methyl ester. The position of the added methoxy group was confirmed by an $\mathrm{HMBC}$ correlation from the emerging methoxy protons $\left(\delta_{\mathrm{H}} 3.91\right.$, in $\left.\mathrm{Me}_{2} \mathrm{CO}-d_{6}\right)$ to the oxygenated olefinic carbon C-4 $\left(\delta_{\mathrm{C}} 161.8\right)$. Treatment of the methyl ester derivative of $\mathbf{1}$ with $(R)$ - and $(S)$-methoxy(trifluoromethyl) phenylacetic acid chloride in dry pyridine gave the $(S)$ - and $(R)$ methoxy(trifluoromethyl)phenylacetic acid diesters, respectively. The differences in chemical shift $\left(\Delta \delta=\delta_{S}-\delta_{R}\right)$ are shown in Figure 1e. From these values, it was found that C- 6 and C-10 were arranged in the $R$ configuration. Given this result, the absolute configurations of 1 were assigned as $2 R, 3 S, 6 R, 7 R$ and $10 R$.

The structure of $\mathbf{1}$ is related to those of the furaquinocins, ${ }^{9-13}$ in particular furaquinocin $\mathrm{D},{ }^{11,12}$ isolated as the secondary metabolite of
Streptomyces. As furaquinocins show cytotoxicity against cancer cells, we evaluated the cytotoxic activity of 1 against human cervical carcinoma HeLa cells by using a (2-(2-methoxy-4-nitrophenyl)-3-(4nitrophenyl)-5-(2,4-disulfophenyl)-2H-tetrazolium monosodium salt (WST-8) colorimetric assay (Cell Counting Kit; Dojindo, Kumamoto, Japan) for $72 \mathrm{~h}$. The results showed that 1 exhibited a weak cytotoxicity, with an $\mathrm{IC}_{50}$ value of $44.4 \mu \mathrm{m}$.

\section{ACKNOWLEDGEMENTS}

This work was supported in part by a grant from the New Energy and Industrial Technology Department Organization of Japan, and a Grant-in-Aid for Scientific Research (23380067 to KS) from the Japan Society for the Promotion of Science.

1 Berdy, J. Bioactive microbial metabolites-a personal view. J. Antibiot. 58, 1-26 (2005).

2 Demain, A. L. \& Sanchez, S. Microbial drug discovery: 80 years of progress. J. Antibiot. 62, 5-16 (2009).

3 Takagi, M. \& Shin-ya, K. Construction of a natural product library containing secondary metabolites produced by actinomycetes. J. Antibiot. 65, 443-447.

4 Omura, S., Muro, T., Namiki, S., Shibata, M. \& Sawada, J. Studies on the antibiotics from Streptomyces spinichromogenes var. kujimyceticus. III The structure of kujimycin A and kujimycin B. J. Antibiot. 22, 629-634 (1969).

5 Furihata, K. \& Seto, H. Constant time HMBC (CT-HMBC), a new HMBC technique useful for improving separation of cross peaks. Tetrahedron Lett. 39, 7337-7340 (1998).

6 Furihata, K. \& Seto, H. J-resolved HMBC, a new NMR technique for measuring heteronucleor long-range coupling constants. Tetrahedron Lett. 40, 6271-6275 (1999).

7 Matsumori, N., Kaneno, D., Murata, M., Nakamura, H. \& Tachibana, K. Stereochemical determination of acyclic structures based on carbon-proton spin-coupling constants. A method of configuration analysis for natural products. J. Org. Chem. 64, 866-876 (1999).

8 Ohtani, I., Kusumi, T., Kashman, Y. \& Kakisawa, H. High-field FT NMR application of Mosher's method. The absolute configurations of marine terpenoids. J. Am. Chem. Soc. 113, 4092-4096 (1991).

9 Řezanka, T. \& Spížek, J. Compounds isolated at the institute of microbiology in 19892001 and future trends. Folia Microbiol. 47, 587-639 (2002).

10 Funayama, S., Ishibashi, M., Anraku, Y., Komiyama, K. \& Ōmura, S. Structures of novel antibiotics, furaquinocins A and B. Tetrahedron Lett. 30, 7427-7430 (1989).

11 Ishibashi, M., Funayama, S., Anraku, Y., Komiyama, K. \& Ōmura, S. Novel antibiotics, furaquinocins C, D, E, F, G and H. J. Antibiot. 44, 390-395 (1991).

12 Dormer, P. G., Smith, A. B., Funayama, S. \& Ōmura, S. Furaquinocins A-G: relative and absolute stereochemistry. Tetrahedron Lett. 33, 1717-1720 (1992).

13 Panthee, S. et al. Furaquinocins I and J: novel polyketide isoprenoid hybrid compounds from Streptomyces reveromyceticus SN-593. J. Antibiot. 64, 509-513 (2011). 